\title{
Exigência de Lisina para Codornas Japonesas em Postura ${ }^{1}$
}

\section{Rogério Pinto ${ }^{2}$, Aloízio Soares Ferreira ${ }^{3}$, Juarez Lopes Donzele ${ }^{3}$, Martinho de Almeida e Silva ${ }^{4}$, Rita da Trindade Ribeiro Nobre Soares ${ }^{5}$, Gislene Santos Custódio ${ }^{6}$, Karine da Silva Pena ${ }^{6}$}

\footnotetext{
RESUMO - Foram utilizadas 300 codornas fêmeas, com idade de 49 dias e peso médio de 138,0 g, durante quatro períodos experimentais de 28 dias. O delineamento experimental foi o em blocos ao acaso, contendo seis níveis de lisina digestível $(0,80,0,90$, $1,00,1,10,1,20$ e $1,30 \%$ ) e cinco repetições, com 10 animais cada. As variáveis estudadas foram: postura (\%), peso do ovo (g), massa de ovo (g de ovos/codorna/dia), consumo alimentar (g), conversão alimentar ( $\mathrm{g}$ de ração/g de ovos), peso final (g) e porcentagem da casca do ovo (\%).Verificou-se efeito quadrático sobre a taxa de postura, massa de ovos e conversão alimentar, e efeito linear sobre o peso dos ovos e consumo alimentar, não tendo sido verificado efeito significativo sobre o peso final das codornas. A exigência em lisina digestível, para codornas japonesas em postura, foi estimada em 1,117\% da ração, correspondendo ao consumo diário de $254 \mathrm{mg}$ de lisina.
}

Palavras-chave: aminoácidos, codornas de postura, Coturnix coturnix japonica, digestibilidade, produção de ovos, proteína ideal

\section{Lysine Requirement for Laying Japanese Quails}

\begin{abstract}
Three hundred 49-days old Japanese female quails, averaging 138.0g, were used to estimate the requirement of digestible lysine level for Japanese quail in completely randomized block design with five replicates of ten females per experimental unit. The treatment consisted six levels of digestible lysine $(0.80,0.90,1.00,1.10,1.20$ and 1.30\%) and the analyzed traits were rate of egg production (\%), egg weight ( $\mathrm{g}$ ), egg mass ( $\mathrm{g}$ of eggs/quail/day), feed intake (g), feed consumption: weight gain ratio (g of diet/g of eggs), final body weight $(\mathrm{g})$ and shell percentage $(\%)$. No signicant effect of treatments on final body weight $(\mathrm{g})$ was observed, but there was quadratic effect for egg production (\%), egg mass ( $\mathrm{g}$ of eggs/quail/day) and feed consumption: gain diet (g of diet/g of eggs) and linear effect on shell egg (\%) and feed intake $(\mathrm{g})$. The estimated requirements of digestible lysine for laying Japanese quail was $1.117 \%$ of the diet, corresponding to a daily intake of $254 \mathrm{mg}$ of digestible lysine.
\end{abstract}

Key Words: amino acid, Coturnix coturnix japonica, digestibility, eggs production, ideal protein, laying quail

\section{Introdução}

A proteína necessária para manutenção do metabolismo corporal das aves e para produção de carne e ovos é proveniente da proteína dietética, cujos aminoácidos são utilizados para exercer inúmeras funções de constituintes primários dos tecidos estruturais e de proteção, como a pele, matriz óssea, ligamentos, tecidos dos órgãos, músculos e penas. Assim, os aminoácidos e peptídeos resultantes dos processos de digestão e absorção dos alimentos podem ser utilizados para várias funções metabólicas e como precursores de inúmeros constituintes corporais não protéicos (Silva, 1997).

Atualmente, as formulações das rações para codornas japonesas baseiam-se no conceito de proteína bruta (PB), que resulta em dietas com o conteúdo aminoacídico superior ou inferior ao exigido, levando a alterações na produção e prejudicando o retorno econômico da atividade, já que, aproximadamente $25 \%$ dos custos da alimentação avícola são decorrentes das fontes protéicas (Albino et al., 1992; Lima, 1994).

Em função das facilidades de compra e de preços compatíveis, atualmente há uma crescente prática de se incorporar aminoácidos sintéticos nas rações, permitindo obter rações de mínimo custo e com teores de proteína bruta inferiores aos recomendados nas tabelas de exigências nutricionais, atendendo também as exigências em aminoácidos essenciais (Conhalato, 1998).

A estimativa das exigências em lisina pode ser o ponto de partida para a formulação de rações corre-

\footnotetext{
${ }^{1}$ Parte da Tese de Doutorado do primeiro autor.

2 Doutor em Zootecnia pelo Programa de Pós graduação da UFV, Rua dos Estudantes, no 25, centro, Viçosa - MG. CEP: 3657.000. E.mail: rpinto@funec.br

3 Professores - Departamento de Zootecnia, UFV- CEP-36570.000, Viçosa - MG.

4 Professor da Universidade Federal de Minas Gerais.

${ }^{5}$ Professora da Universidade Estadual do Norte Fluminense.

${ }^{6}$ Estudantes de Zootecnia, CCA, DZO - Universidade Federal de Viçosa.
} 
tamente balanceadas, com base no conceito de proteína ideal, pois a lisina tem sido o aminoácido de referência no estabelecimento das exigências de proteína e de outros aminoácidos (Baker \& Han, 1994). Isto significa que qualquer aminoácido pode se relacionar à lisina (Firman \& Boling, 1998), de modo que, se a sua exigência for alterada por algum fator dietético, genético e/ ou ambiental, alterar-se-à concomitantemente os outros aminoácidos (Baker \& Han, 1994).

Pack (1995) cita que as proporções ideais devem permanecer bastante estáveis, independentemente de alterações nos planos de nutrição aminoacídica, constituindo-se em grande vantagem o conceito da proteína ideal, pois poderá ser adaptada facilmente a uma variedade de situações.

O conceito de proteína ideal tem sido definido como sendo o balanço teoricamente exato de aminoácidos para o atendimento das necessidades das aves, sem promover excessos ou deficiências, e com mínimos desvios dos aminoácidos essenciais para produção de energia, síntese de aminoácidos não essenciais e catabolismo, melhorando o custo benefício com a formulação da ração e reduzindo a poluição ambiental por nitrogênio (Firman \& Boling, 1998).

Assim, verifica-se ser necessário determinar as exigências de lisina digestível para codornas japonesas na fase de postura.

\section{Material e Métodos}

O experimento foi realizado num galpão adaptado para criação de codornas na seção de Avicultura do Departamento de Zootecnia do Centro de Ciências Agrárias da Universidade Federal de Viçosa, no período de setembro a dezembro de 2001.

Foram utilizadas 300 codornas fêmeas (Coturnix coturnix japonica), com a idade inicial de 49 dias e peso médio inicial de $138,0 \mathrm{~g}$, durante quatro períodos de 28 dias.

O delineamento experimental utilizado foi em blocos ao acaso, contendo seis níveis de lisina digestível $(0,80,0,90,1,00,1,10,1,20$ e $1,30 \%)$ e cinco repetições, com 10 animais por unidade experimental. O delineamento experimental foi em blocos ao acaso, para evitar o efeito do posicionamento das gaiolas nos andares e nas baterias sobre os tratamentos.

As aves foram alojadas em gaiolas de arame galvanizado com dimensões de 1,0 m de comprimen- to $\mathrm{x} 0,25 \mathrm{~m}$ de largura $\mathrm{x} 0,20 \mathrm{~m}$ de altura, dispostas em três andares, montadas em esquema de escada. Cada gaiola foi subdividida em duas repartições iguais de 0,50 m. Sobre o piso de cimento, logo abaixo das gaiolas, foi colocada uma camada de pó de madeira, para absorção da umidade das fezes. O comedouro e o bebedouro utilizados foram do tipo calha, em chapa metálica galvanizada, ambos percorrendo a extensão das gaiolas, sendo o comedouro na parte frontal e o bebedouro na parte posterior da gaiola.

Os animais foram submetidos a seis rações (Tabela 1), formuladas à base de milho, farelo de soja e proteinoso (glúten de milho), contendo 19,56\% de proteína bruta $(\mathrm{PB})$ e $2.900 \mathrm{kcal}$ de $\mathrm{EM} / \mathrm{kg}$ de ração.

Para compor os tratamentos experimentais, as rações foram suplementadas com L-Lisina. $\mathrm{HCl}$ $(78,4 \%)$, em substituição ao amido de milho, correspondendo aos níveis de, 0,800, 0,900, 1,000, $1,100,1,200$ e $1,300 \%$ de lisina digestível permanecendo as rações isocalóricas.

Em todas as rações experimentais, foram mantidas as relações entre os aminoácidos: lisina, constantes no NRC (1994), exceto para metionina mais cistina digestível: lisina digestível, que em todas as rações, correspondeu à relação de 0,80 , proposta por Pinto et al. (2002), segundo o conceito de proteína ideal proposto por Parsons \& Baker (1994).

Para composição das rações experimentais e manutenção das relações entre os aminoácidos com a lisina foram utilizados aminoácidos sintéticos, em substituição ao amido de milho.

As rações foram formuladas com base no conteúdo aminoacídico digestível verdadeiro dos alimentos, determinados pelo método de alimentação precisa de Sibbald, utilizando galos cecectomizados, apresentado em Rostagno et al. (2000), e as exigências nutricionais das codornas japonesas em postura, constantes no National Research Council (1994), exceto para proteína bruta (PB), lisina e metionina mais cistina.

Os bebedouros foram limpos periodicamente e o fornecimento de água para as codornas foi corrente.

O programa de luz utilizado foi de 17 (dezessete) horas de luz, por meio de controlador de luz do tipo "timer".

As mensurações de temperatura e umidade dentro do galpão foram registradas por meio de termômetros de máxima e mínima e de bulbo seco e bulbo úmido.

Foram analisados taxa de postura $(\%)$, peso médio

R. Bras. Zootec., v.32, n.5, p.1182-1189, 2003 
Tabela 1 - Composição percentual e calculada das rações experimentais

Table 1 - Percentual and calculated composition of the experimental diets

\begin{tabular}{|c|c|c|c|c|c|c|}
\hline \multirow[t]{2}{*}{$\begin{array}{l}\text { Ingredientes } \\
\text { Ingredients }\end{array}$} & \multicolumn{6}{|c|}{$\begin{array}{l}\text { Níveis de lisina digestível nas rações }(\%) \\
\text { Levels of digestible lysine in the diets }\end{array}$} \\
\hline & 0,800 & 0,900 & 1,000 & 1,100 & 1,200 & 1,300 \\
\hline Milho (Corn) & 60,259 & 60,259 & 60,259 & 60,259 & 60,259 & 60,259 \\
\hline Farelo de Soja (Soybean meal) & 24,996 & 24,996 & 24,996 & 24,996 & 24,996 & 24,996 \\
\hline Glúten de Milho (Corn gluten) (60\%) & 5,081 & 5,081 & 5,081 & 5,081 & 5,081 & 5,081 \\
\hline Amido (Starch) & 2,000 & 1,791 & 1,491 & 1,033 & 0,562 & 0,132 \\
\hline Fosfato bicálcico (Dicalcium phosphate) & 1,331 & 1,331 & 1,331 & 1,331 & 1,331 & 1,331 \\
\hline Calcário (Limestone) & 5,389 & 5,389 & 5,389 & 5,389 & 5,389 & 5,389 \\
\hline Óleo vegetal (Oil) & 0,447 & 0,447 & 0,447 & 0,447 & 0,447 & 0,447 \\
\hline $\operatorname{Sal}($ Salt $)$ & 0,288 & 0,288 & 0,288 & 0,288 & 0,288 & 0,288 \\
\hline Mistura mineral ${ }^{1}$ (Mineral mix) & 0,050 & 0,050 & 0,050 & 0,050 & 0,050 & 0,050 \\
\hline Mistura vitamínica $^{2}$ (Vitamin mix) & 0,100 & 0,100 & 0,100 & 0,100 & 0,100 & 0,100 \\
\hline $\mathrm{BHT}^{3}$ & 0,010 & 0,010 & 0,010 & 0,010 & 0,010 & 0,010 \\
\hline DL-Metionina (99\%) (DL-Methionine) & 0,049 & 0,130 & 0,207 & 0,289 & 0,369 & 0,404 \\
\hline L-Lisina.Hcl $($ L-Lysine $\mathrm{HCl})(78,4 \%)$ & 0,000 & 0,128 & 0,258 & 0,384 & 0,512 & 0,640 \\
\hline L-Triptofano (L-Tryptophan) (99\%) & 0,000 & 0,000 & 0,000 & 0,000 & 0,015 & 0,034 \\
\hline L-Treonina (L-Threonine) $(99 \%)$ & 0,000 & 0,000 & 0,000 & 0,063 & 0,126 & 0,189 \\
\hline L-Valina (L-Valine) $(99 \%)$ & 0,000 & 0,000 & 0,000 & 0,094 & 0,186 & 0,278 \\
\hline L-Arginina (L-Arginine) $(99 \%)$ & 0,000 & 0,000 & 0,093 & 0,186 & 0,279 & 0,372 \\
\hline \multirow[t]{2}{*}{ Total } & 100,00 & 100,00 & 100,00 & 100,00 & 100,00 & 100,00 \\
\hline & \multicolumn{6}{|c|}{$\begin{array}{l}\text { Composição calculada } \\
\text { Calculated composition }\end{array}$} \\
\hline Proteína (Protein) $(\%)$ & 19,556 & 19,556 & 19,556 & 19,556 & 19,556 & 19,556 \\
\hline E M ( kcal $/ \mathrm{kg})$ (Metabolizable energy) & 2.900 & 2.900 & 2.900 & 2.900 & 2.900 & 2.900 \\
\hline Cálcio (Calcium) $(\%)$ & 2,500 & 2,500 & 2,500 & 2,500 & 2,500 & 2,500 \\
\hline Fósforo disponível (\%) & 0,350 & 0,350 & 0,350 & 0,350 & 0,350 & 0,350 \\
\hline \multirow{3}{*}{$\begin{array}{l}\text { Available phosphorus } \\
\text { Sódio (Sodium) (\%) }\end{array}$} & & & & & & \\
\hline & 0,150 & 0,150 & 0,150 & 0,150 & 0,150 & 0,150 \\
\hline & \multicolumn{6}{|c|}{$\begin{array}{c}\text { Aminoácidos digestíveis }{ }^{4} \\
\text { Digestible amino acids }\end{array}$} \\
\hline Lisina $($ Lysine $)(\%)$ & 0,800 & 0,900 & 1,000 & 1,100 & 1,200 & 1,300 \\
\hline Met.+ Cistina $(M e t+C y s)(\%)$ & 0,640 & 0,720 & 0,800 & 0,880 & 0,960 & 1,040 \\
\hline Triptofano (Tryptophan) (\%) & 0,192 & 0,192 & 0,192 & 0,192 & 0,206 & 0,224 \\
\hline Treonina (Threonine) $(\%)$ & 0,750 & 0,750 & 0,750 & 0,809 & 0,866 & 0,924 \\
\hline Metionina (Methionine) (\%) & 0,386 & 0,434 & 0,483 & 0,531 & 0,579 & 0,627 \\
\hline Arginina (Arginine) $(\%)$ & 1,172 & 1,172 & 1,260 & 1,389 & 1,512 & 1,638 \\
\hline Valina (Valine) $(\%)$ & 0,918 & 0,918 & 0,918 & 1,012 & 1,104 & 1,196 \\
\hline
\end{tabular}

1 Conteúdo/kg de mistura vitamínica (Content/kg of vitamin mix): Vit. A - 12.000.000 U.I.; Vit. D - 3.600 .000 U.I.; Vit. B - 2.500 mg; Vit $\mathrm{B}_{2}-8.000 \mathrm{mg}$; Vit. B6 - $5.000 \mathrm{mg}$; Ác. pantotênico (pantothenic acid) - $12.000 \mathrm{mg}$; Biotina (biotin) - $200 \mathrm{mg}$; Vit. $\mathrm{K}^{3}-3.000 \mathrm{mg}$; Ác. fólico (folic acid) - 1.500 mg; Ác.nicotínico (nicotinic acid) - 40.000 mg; Vit. $B_{12}-20.000$ mcg; Selênio (seleniun) - 150 mg; Veículo, q.s.p. - 1000 g.; ${ }^{2}$ Conteúdo/kg de mistura mineral (Content/kg of mineral mix): Manganês (manganese) - 160,0 g; Ferro (iron) - 100,0 g; Cobre (copper) - 20,0 g; Zinco (zinc) - 100,0 g; Cobalto (cobalt) - 2,0 g; lodo (iodine) - 2,0 g; Veículo (vehicle)q.s.p. - 1000 g.; 3 Antioxidante (Antioxidant); ${ }^{4}$ Conteúdo aminoacídico digestível verdadeiro, obtido por meio do método de alimentação precisa de Sibbald, utilizando galos cecectomizados, constantes em Rostagno et al. (2000)(True digestible amino acid content, obtained by means of feeding method of Sibbald, using cecectomized roosters, constant in Rostagno et al. [2000]).

dos ovos (g), massa de ovos (g de ovos/codorna/dia), consumo de ração (g/ave/dia), conversão alimentar (g de ração/g de ovo), peso final $(\mathrm{g})$ e porcentagem da casca do ovo.

Para o controle de o consumo alimentar as rações de cada repetição dos tratamentos foram acondicionadas em baldes plásticos, devidamente identificados, sendo o consumo de ração medido ao término de cada período de 28 dias, por meio da diferença entre a ração fornecida e a sobra. As aves mortas e as sobras das rações foram pesadas para ajustar o controle do consumo, ganho de peso dos animais, postura e conversão alimentar ao término de cada período.

A coleta dos ovos foi feita diariamente às 17:00 $\mathrm{h}$ e a produção de ovos foi obtida em porcentagem ave/dia.

Para obtenção dos dados de peso médio dos ovos, estes foram coletados e pesados em balança de precisão de $0,01 \mathrm{~g}$ nos quatro últimos dias de cada 
período, os ovos de cada unidade experimental. Após a pesagem os ovos foram quebrados e suas cascas mantidas identificadas para serem secas e pesadas, obtendo-se assim a porcentagem das cascas.

Para obtenção da massa de ovos tomou-se a produção multiplicada pelo peso médio dos ovos.

A conversão alimentar foi obtida dividindo-se o consumo médio diário de ração pela produção média de ovos em g (conversão $\mathrm{g} / \mathrm{g}$ ).

Os dados foram analisados utilizando-se o Programa Sistema para Análises Estatísticas e Genética (SAEG), Universidade Federal de Viçosa (1997). A exigência em lisina digestível para as codornas japonesas em postura foi estabelecida por equações de regressão, respeitando-se a interpretação biológica das variáveis.

\section{Resultados e Discussão}

Os dados de temperatura máxima e mínima médias, e da umidade relativa do ar, no interior do galpão, são apresentados na Tabela 2.

A temperatura máxima verificada em todo o período experimental esteve acima daquelas observadas na zona de conforto das codornas em postura (21 a $25 \mathrm{C}^{\circ}$ ), segundo Reis (1980). Além disso, a flutuação térmica semanal verificada no galpão experimental foi de 23,19 a $30,5 \mathrm{C}^{\circ}$, ocorrendo grande variação térmica em todo período experimental. Esta alta temperatura média, acima da zona de termoneutralidade, pode ter sido responsável pela diminuição do consumo de ração pelas codornas, numa tentativa de manterem a temperatura corporal dentro de limites homeostáticos.

Na Tabela 3, são apresentados os valores médios da taxa de postura, peso do ovo, massa do ovo, consumo alimentar, conversão alimentar, peso final e porcentagem da casca do ovo das codornas japonesas alimentadas com rações de diferentes níveis de lisina digestível.

Verificou-se efeito quadrático $(\mathrm{P}<0,06)$, dos níveis de lisina digestível sobre a taxa de postura, de acordo com a equação $\mathrm{Y}=4,20165+153,504 \mathrm{X}$ $73,4263 X^{2}\left(R^{2}=0,84\right)$, Tabela 3 e Figura 1.

O nível de lisina digestível que maximizou a taxa de postura foi de $1,045 \%$. Este resultado é semelhante ao apresentado por March \& Biely (1972) e Goulart (1997), que em experimento para determinar os níveis de lisina para galinhas poedeiras, também verificaram melhora na taxa de postura com o aumento dos níveis de lisina até um ponto de função máxima.

Entretanto, Carlson \& Ghenthner(1969) e Latshaw (1976), também trabalhando com galinhas poedeiras leves, não verificaram efeito significativo dos níveis de lisina utilizados sobre a taxa de postura.

Para o peso dos ovos $(\mathrm{g})$, verificou-se efeito linear positivo $(\mathrm{P}<0,01)$ dos níveis de lisina digestível, segundo a equação $\mathrm{Y}=8,58496+$ $1,56058 \mathrm{X}\left(\mathrm{R}^{2}=0,74\right)$, Tabela 3 e Figura 2. Este resultado esta de acordo com Latshaw (1976), que verificou ser necessário maior exigência em lisina para o peso de ovo do que para máxima produção de ovos pelas aves. O resultado obtido para o peso de ovos demonstrou que o nível de lisina digestível utilizado não foi suficiente para promover peso máximo dos ovos.

Os níveis de lisina digestível influenciaram a massa de ovos $(\mathrm{P}<0,05)$ de forma quadrática, segundo a equação $\mathrm{Y}=-2,37283+19,8371 \mathrm{X}-8,87569 \mathrm{X}^{2}\left(\mathrm{R}^{2}=0,68\right)$, Tabela 3 e Figura 3. O nível de lisina digestível que

\begin{tabular}{|c|c|c|c|}
\hline \multirow[t]{2}{*}{$\begin{array}{l}\text { Idade das aves (dias) } \\
\text { Bird age (days) }\end{array}$} & \multicolumn{2}{|c|}{$\begin{array}{c}\text { Temperatura do } \operatorname{ar}\left(\mathrm{C}^{\circ}\right) \\
\text { Air temperature }\end{array}$} & \multirow[t]{2}{*}{$\begin{array}{c}\text { Umidade relativa }(\%) \\
\text { Relative humidity }\end{array}$} \\
\hline & $\begin{array}{l}\text { Máxima média } \\
\text { Maximum average }\end{array}$ & $\begin{array}{l}\text { Mínima média } \\
\text { Minimum average }\end{array}$ & \\
\hline $49-62$ & $28,5 \pm 0,50$ & $22,70 \pm 0,30$ & $66,70 \pm 6,25$ \\
\hline $63-76$ & $29,0 \pm 0,75$ & $24,00 \pm 0,42$ & $68,40 \pm 6,42$ \\
\hline $77-90$ & $30,0 \pm 0,50$ & $25,13 \pm 0,70$ & $60,23 \pm 6,13$ \\
\hline $91-104$ & $28,0 \pm 0,75$ & $25,56 \pm 0,75$ & $72,50 \pm 6,07$ \\
\hline $105-118$ & $28,5 \pm 0,50$ & $24,86 \pm 1,11$ & $68,14 \pm 5,51$ \\
\hline $119-132$ & $29,0 \pm 0,57$ & $23,72 \pm 0,53$ & $70,00 \pm 10,28$ \\
\hline $133-146$ & $29,5 \pm 0,50$ & $25,14 \pm 015$ & $64,71 \pm 11,43$ \\
\hline $147-161$ & $28,5 \pm 0,75$ & $23,21 \pm 0,30$ & $67,04 \pm 4,29$ \\
\hline
\end{tabular}

R. Bras. Zootec., v.32, n.5, p.1182-1189, 2003 
Tabela 3 - Efeito dos níveis de lisina digestível sobre a taxa de postura (\%), peso do ovo (g), massa de ovo (g), consumo alimentar (g), conversão alimentar $(\mathrm{g} / \mathrm{g})$, peso final $(\mathrm{g})$ e casca do ovo (\%) de codornas japonesas em postura

Table 3 - Effect of Lysine levels on the laying ratio (\%), egg weight (g), egg mass (g), feed intake (g), feed: gain ratio (g/g), final weight $(g)$, egg shell (\%) of laying Japanese quail

\begin{tabular}{|c|c|c|c|c|c|c|c|c|}
\hline $\begin{array}{l}\text { Lisina total } \\
\text { Total lysine }\end{array}$ & $\begin{array}{c}\text { Lisina } \\
\text { digestível } \\
\text { Digestible } \\
\text { lysine }\end{array}$ & $\begin{array}{l}\text { Produção } \\
\text { de ovos } \\
\text { Laying } \\
\text { eggs }\end{array}$ & $\begin{array}{c}\text { Peso } \\
\text { de ovo } \\
\text { Egg } \\
\text { weight }\end{array}$ & $\begin{array}{c}\text { Massa } \\
\text { de ovo } \\
\text { Egg } \\
\text { mass }\end{array}$ & $\begin{array}{l}\text { Consumo } \\
\text { alimentar } \\
\text { Feed } \\
\text { intake }\end{array}$ & $\begin{array}{l}\text { Conversão } \\
\text { alimentar } \\
\text { Feed:gain } \\
\text { ratio }\end{array}$ & $\begin{array}{l}\text { Peso } \\
\text { final } \\
\text { final } \\
\text { weight }\end{array}$ & $\begin{array}{c}\text { Casca } \\
\text { do ovo } \\
\text { egg } \\
\text { shell }\end{array}$ \\
\hline 0,890 & 0,800 & 80,96 & 9,88 & 7,97 & 22,13 & 2,79 & 148,41 & 8,64 \\
\hline 0,998 & 0,900 & 81,95 & 9,89 & 8,11 & 21,54 & 2,66 & 144,87 & 8,55 \\
\hline 1,100 & 1,000 & 83,48 & 9,98 & 8,32 & 21,90 & 2,64 & 148,42 & 8,74 \\
\hline 1,200 & 1,100 & 85,33 & 10,59 & 9,04 & 23,14 & 2,57 & 153,56 & 8,36 \\
\hline 1,300 & 1,200 & 83,21 & 10,50 & 8,74 & 22,70 & 2,60 & 147,41 & 8,16 \\
\hline 1,400 & 1,300 & 79,33 & 10,47 & 8,31 & 23,36 & 2,82 & 149,24 & 8,39 \\
\hline $\begin{array}{l}\text { Coeficiente de variação } \\
\text { Coefficient of variation }\end{array}$ & & 6,147 & 1,369 & 5,825 & 3,447 & 6,821 & 2,962 & 3,206 \\
\hline $\begin{array}{l}\text { Significância } \\
\text { Significance }\end{array}$ & & $\mathrm{P}<0,06 * *$ & $\mathrm{P}<0,01^{*}$ & $\mathrm{P}<0,05^{*} *$ & $\mathrm{P}<0,01^{*}$ & $\mathrm{P}<0,01 * *$ & n.s & $\mathrm{P}<0,05^{*}$ \\
\hline
\end{tabular}

Efeito linear pelo teste $\mathrm{F}$ (Linear effect by $\mathrm{F}$ test); ${ }^{* *}$ Efeito Quadrático pelo teste $\mathrm{F}$ (Quadratic effect by $\mathrm{F}$ test); n.s. - não-significativo (Not significant).

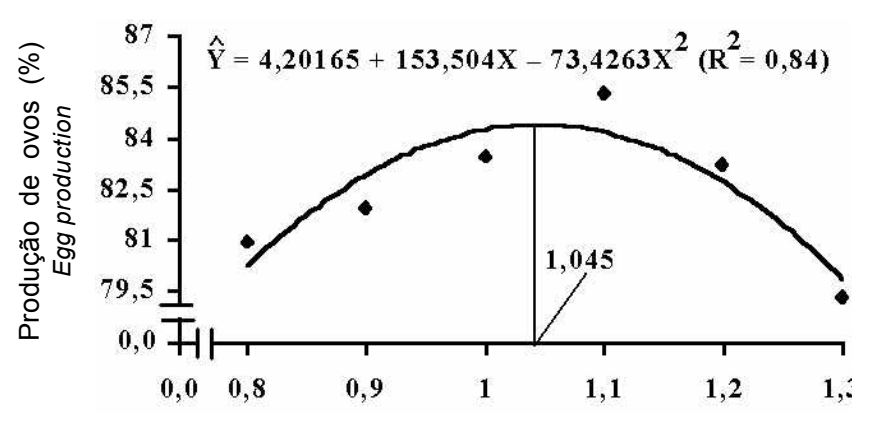

Níveis de lisina digestível (\%)

Digestible lysine levels

Figura 1 - Efeito dos níveis de lisina digestível sobre a postura das codornas japonesas.

Figure 1 - Effect of digestible lysine levels on egg production of Japanese quails.

maximizou a massa de ovos foi $1,117 \%$.

Entretanto, Weerden \& Schutte (1980) e Goulart (1997) verificaram melhora linear para massa dos ovos de galinhas poedeiras com o aumento dos níveis de lisina na ração.

Os níveis de lisina digestível utilizados influenciaram o consumo de ração $(\mathrm{P}<0,01)$, segundo a equação $\mathrm{Y}=19,1738+3,1386 \mathrm{X} \quad\left(\mathrm{R}^{2}=0,65\right)$, Tabela $3 \mathrm{e}$ Figura 4.

Este efeito pode ser explicado pelo aumento no consumo de lisina nas rações, já que foram

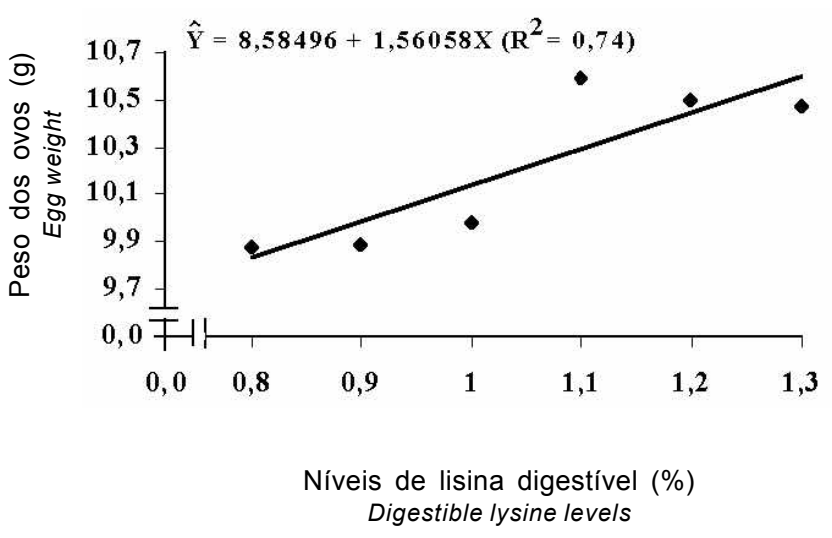

Figura 2 - Efeito dos níveis de lisina digestível sobre o peso dos ovos das codornas.

Figure 2 - Effect of digestible lysine levels on egg weight of Japanese quails.

isocalóricas e isoprotéicas. Dessa forma, Goulart (1997), Chi \& Speers (1972) e Weerden \& Shutte (1970) verificaram aumento no consumo de lisina, para galinhas poedeiras alimentadas com rações que possuíam os maiores níveis de lisina. Entretanto, Bertechini et al. (1995) não verificaram efeito dos níveis de lisina sobre o consumo alimentar.

Os níveis de lisina digestível apresentaram um efeito quadrático $(\mathrm{P}<0,01)$ sobre a conversão alimentar, sendo o nível que proporcionou a melhor conversão alimentar de $1,050 \%$, segundo a equação 


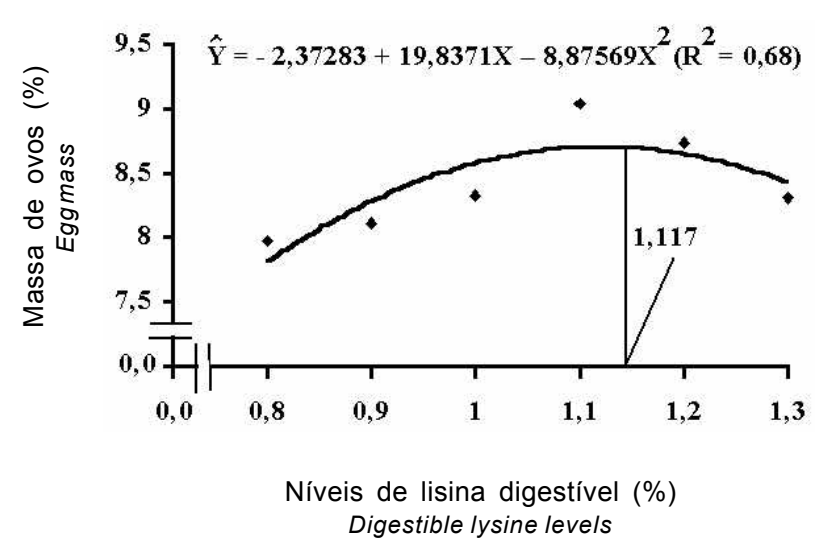

Figura 3 - Efeito dos níveis de lisina digestível sobre a massa de ovos das codornas.

Figure 3 - Effect of digestible lysine levels on egg mass of Japanese quails.

$\mathrm{Y}=6,45701-7,58143 \mathrm{X}+3,51166 \mathrm{X}^{2}\left(\mathrm{R}^{2}=0,87\right)$, Tabela 3; Figura 5.

Já Goulart (1997), Bertechini et al. (1995) e Blair (1976), todos trabalhando com galinhas poedeiras, verificaram melhora na conversão alimentar quando os níveis de lisina da dieta era aumentada. Entretanto, Chi \& Speers (1985) e Nathanael \& Sell (1980) não verificaram melhora na conversão alimentar de galinhas poedeiras com o aumento dos níveis de lisina nas dietas.

Não foi verificado efeito dos níveis de lisina $(\mathrm{P}>0,05)$ sobre o peso final das codornas. Este resultado difere dos apresentados por Goulart (1997) e Chi \& Speers (1985), que verificaram aumento no peso das galinhas poedeiras devido ao aumento dos níveis de lisina nas dietas.

Um fator que pode ter contribuído para que não houvesse efeito dos níveis de lisina sobre o peso final das codornas japonesas em postura foi a baixa capacidade de deposição tecidual desta espécie, segundo Shin \& Vorha (1984). Além disso, o pequeno peso corporal apresentado pelas codornas em relação à massa de ovos produzida diariamente, pode indicar que a exigência para produção de ovos é predominante à do ganho de peso, estando de acordo com Lesson (1999) e Conn \& Zhang (1999).

A porcentagem de casca dos ovos (\%) diminuiu de forma linear $(\mathrm{P}<0,05)$ com o aumento dos níveis de lisina digestível, de acordo com a equação $\mathrm{Y}=9,31135-0,8002 \mathrm{X}\left(\mathrm{R}^{2}=0,51\right)$, Tabela 3 e Figura 6 .

Esta diminuição na porcentagem da casca dos

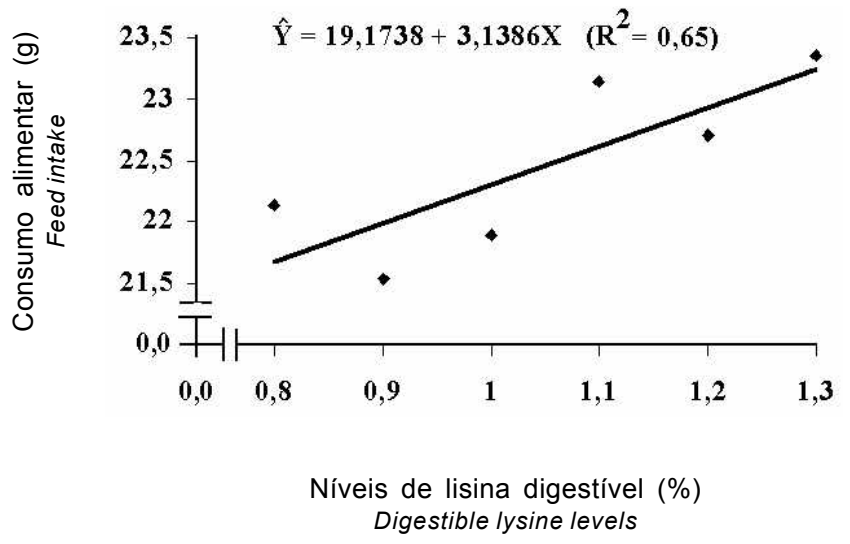

Figura 4 - Efeito dos níveis de lisina digestível sobre o consumo alimentar das codornas.

Figure 4 - Effect of digestible lysine levels on feed intake of Japanese quails.

ovos pode ser explicada pelo aumento no peso e da produção dos ovos, com o aumento nos níveis de lisina utilizados. A maior intensidade de produção pode ter ocasionado menor permanência dos ovos no útero (glândula da casca). Os ovos de codorna levam em média de 18 às $20 \mathrm{~h}$ para serem totalmente formados, significando que no pico de postura, a codorna pode botar até dois ovos. Isto implica em maior demanda de cálcio plasmático para formação da casca. Embora a porcentagem da casca dos ovos tenha diminuído com o aumento dos níveis de lisina da ração, o peso da casca dos ovos em valores absolutos aumentou quando se comparou a porcentagem da casca nos níveis extremos utilizados $(0,800 \%$ - peso de $0,854 \mathrm{~g}$; $1,300 \%$ - peso de $0,878 \mathrm{~g}$ ). Mesmo possuindo cascas mais pesadas, os ovos maiores apresentaram menor teor de casca em relação aos ovos menores, o que implica em cascas mais finas e pacíveis de quebra.

Tendo em vista os resultados obtidos, o nível de lisina digestível estimado para codornas japonesas em postura foi de $1,117 \%$ da ração. Este nível foi o que proporcionou a melhor produção em massa de ovos, já que este parâmetro constitui-se de grande importância para poedeiras. Além disso, este nível atende às exigências de maior importância, como a taxa de postura $(1,045 \%$ de lisina digestível) e conversão alimentar $(1,050 \%$ de lisina digestível).

A exigência de $1,117 \%$ de lisina digestível representa $1,273 \%$, de lisina total, sendo superior às apresentadas pelo NRC (1994), 1,00\%; Allen e Young (1980), 0,86\%; Reis (1980), 0,85\%; Shin \& Vorha

R. Bras. Zootec., v.32, n.5, p.1182-1189, 2003 


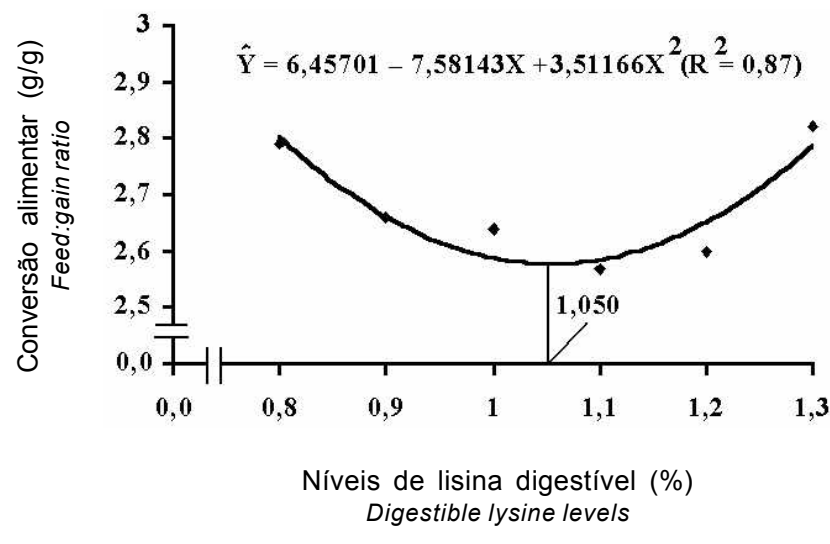

Figura 5 - Efeito dos níveis de lisina digestível sobre a conversão alimentar $(\mathrm{g} / \mathrm{g})$ para as codornas

Figure 5 - Effect of digestible lysine levels on feed: gain ratio. of Japanese quails.

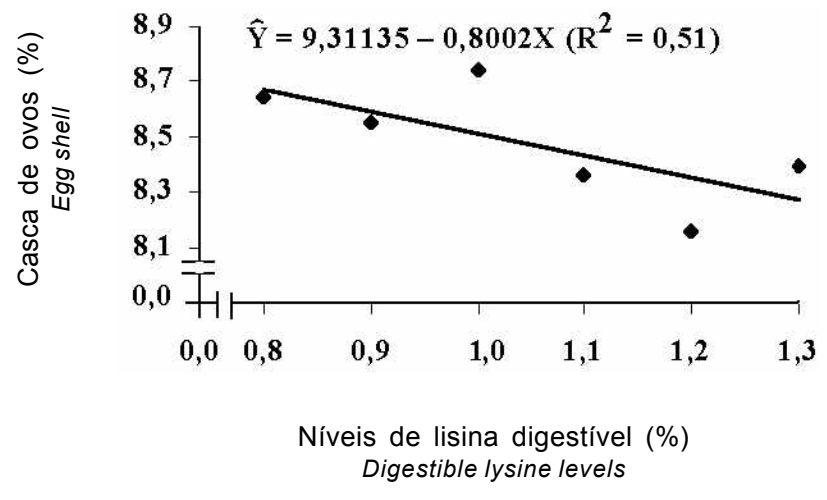

Figura 6 - Efeito dos níveis de lisina digestível sobre a porcentagem da casca dos ovos das codornas.

Figure 6 - Effect of digestible lysine levels on egg shell percentage of Japanese quails.
(1984), 1,15\% de lisina total. Esta maior exigência em lisina verificada pode ser atribuída ao menor nível de proteína bruta utilizado nas rações experimentais, quando comparadas ás utilizadas por estes autores.

\section{Conclusões}

A exigência em lisina digestível estimada para codornas japonesas em postura foi de $1,117 \%$ da ração, correspondendo ao consumo diário de $254 \mathrm{mg}$ de lisina digestível.

\section{Literatura Citada}

ALBINO, L.F.T.; ROSTAGNO, H.S.; SANT'ANNA, R. et al. Determinação dos valores de aminoácidos metabolizável e proteína digestiva de alimentos para aves. Revista da Sociedade Brasileira de Zootecnia, v.21, n.6, p.1059-1068, 1992.

ALLEN, N.; YOUNG, R.J. Studies on the amino acid and protein requirements of laying Japanese quail (Coturnix coturnix japonica ). Poultry Science, v.59, n.9, p.2029-2037, 1980.

BACKER, D.H.; HAN, Y. Ideal amino acid profile for chickens during the first three weeks posthatching. Poultry Science, v.73, n.11, p.1441-1447, 1994.

BERTECHINI, A.G.; HOSSAIN, S.M.; LIRA, VV.M. Níveis de lisina para poedeiras comerciais leves na fase de pico de postura. In: CONFERÊNCIA APINCO DE CIÊNCIA E TECNOLOGIA, 1995, Curitiba. Anais... Curitiba: 1995. p.95.

BLAIR, R.; LEE, D.J.; FISHER, C. et al. Responses of laying hens to slow-protein diet supplemented with essencial amino acids, L-glutamic and/or intact protein. British Poultry Science, v.17, n.4, p.427-440, 1976.

CARLSON, C.W.; GUENTHNER, E. Response of laying hens fed typical corn-soy diets to supplements of methionine and

R. Bras. Zootec., v.32, n.5, p.1182-1189, 2003 lysine. Poultry Science, v.48, n.1, p.137-143, 1969.

CHI, M.S.; SPEERS, G.M. Effects of dietary protein and lysine levels on plasma amino acids, nitrogen retention and egg production in laying hens. Journal of Nutrition, v. 106, n.8, p.1192-11201, 1976.

CONN, C.; ZHANG, B. Ideal amino acid profile for layers examined. Feedstuffs, April - 5, p.13-15 e 31, 1999.

CONHALATO, G.S. Exigência de lisina digestível para frangos de corte machos. Viçosa, MG: Universidade Federal de Viçosa, 1998. 79p. Dissertação (Mestrado em Zootecnia) - Universidade Federal de Viçosa, 1998.

FIRMAN, J.D.; BOLING, S.D. Ideal protein in turkeys. Poultry Science, v.77, n.1, p.105-110, 1998.

GOULART, C.C. Exigência nutricional de lisina para poedeiras leves e semipesadas. Viçosa, MG: Universidade Federal de Viçosa, 1997. 51p. Dissertação (Mestrado em Zootecnia) - Universidade Federal de Viçosa, 1997.

LESSON, S. Proteína (aminoácidos) para reprodutoras pesadas. In: SIMPÓSIO INTERNACIONAL SOBRE NUTRIÇÃO DE AVES. , 1999, Campinas. Anais... Campinas: FACTA, 1999. p.85-95.

LATSHAW, J.D. Lysine requirement of hens fed diets with corn as major cereal grain. Poultry Science, v.55, n.6, p.2348$2353,1976$.

LIMA, I. Níveis nutricionais utilizados nas rações pela industria avícola. In: SINPÓSIO INTERNACIONAL SOBRE EXIGÊNCIAS NUTRICIONAIS DE AVES E SUÍNOS. 1996, Viçosa, MG. Anais ... Viçosa: Universidade Federal de Viçosa, 1996. p.389-402.

MARCH, B.E.; BIELY, J. The effects of protein level and amino acid balance in wheat-based laying rations. Poultry Science, v.51, n.1, p.547-557, 1972.

NATHANAEL, A.S.; SELL, J.L. Quantitative measurements of lysine requirements of laying hen. Poultry Science, v.59, n.3, p.594-597, 1980.

NATIONAL RESEARCH COUNCIL - NRC. Nutrient requirements of poultry. Washington, D.C.: National Academic Press, 1994. p.44-45. 
PACK, M. Proteína ideal para frangos de corte. Conceitos e posição atual. In: CONFERÊNCIA APINCO DE CIÊNCIA E TECNOLOGIA AVÍCOLA, 1995, Curitiba. Anais... APINCO, 1995. p.95-110.

PARSONS, C.M.; BAKER, D.H. The concept and use of ideal proteins in the feeding of non ruminants. In: SIMPÓSIO INTERNÁCIONAL DE PRODUÇÃO DE NÃO RUMINANTES, 1994, Maringá. Anais... Maringá: Sociedade Brasileira de Zootecnia, 1994. p.119-128.

PINTO, R.; FERREIRA, A.S.; DONZELE, J.L. et al. Exigência nutricional em metionina + cistina para codornas japonesas em postura. In: REUNIÃO ANUAL DA SOCIEDADE BRASILEIRA DE ZOOTECNIA, 39., 2002, Recife. Anais... Recife: Sociedade Brasileira de Zootecnia/TechnoMEDIA, [2002]. CD-ROM.Não-ruminantes.

REIS, L.F.S.D. Codornizes, criação e exploração. Lisboa, Agros, 10, 1980. 222p.

ROSTAGNO, H.S.; ALBINO, L.F.T.; DONZELE, J.L. et al. Composição de alimentos e exigências nutricionais; (Tabelas Brasileiras). Viçosa, MG: Universidade Federal de Viçosa, 2000. 141p.
SHIM, K.F.; VORHA, P. A Review of the nutrition of Japanese quail. World's Poultry Science Journal, v.40, n.3, p.261274, 1984.

SILVA, S.H.M. Exigências em metionina + cistina para duas marcas comerciais de frangos de corte. Viçosa, MG: Universidade Federal de Viçosa, 1997. 52p. Dissertação (Mestrado em Zootecnia) - Universidade Federal de Viçosa, 1997.

UNIVERSIDADE FEEDERAL DE VIÇOSA - UFV. SAEG Sistema para análise estatística e genética. Versão 8.0. Viçosa, MG: Fundação Arthur Bernardes, 1999.

WEERDEN, E.J.; Van SHUTTE, J.B. Lysine requirement of the laying hen. Archieve Geflügelk, v.44, n.1, p.36-40, 1980.

Recebido em: 14/08/02

Aceito em: 13/11/02 